\title{
Southern Ocean overturning across streamlines in an eddying simulation of the Antarctic Circumpolar Current
}

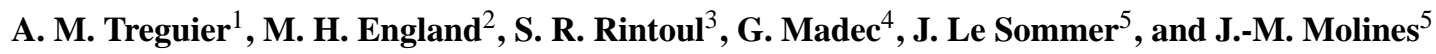 \\ ${ }^{1}$ Laboratoire de Physique de Oceans, CNRS-IFREMER-UBO, Plouzané, France \\ ${ }^{2}$ Climate Change Research Centre (CCRC), University of New South Wales, Sydney, Australia \\ ${ }^{3}$ CSIRO Wealth from Oceans National Research Flagship and Antarctic Climate and Ecosystems CRC, Hobart, Australia \\ ${ }^{4}$ Laboratoire d'Océanographie et du Climat: Experimentations et Approches Numériques, Pierre and Marie Curie University, \\ Paris, France \\ ${ }^{5}$ Laboratoire des Ecoulements Geophysiques et Industriels, Joseph Fourier University, Grenoble, France
}

Received: 9 July 2007 - Published in Ocean Sci. Discuss.: 17 July 2007

Revised: 5 December 2007 - Accepted: - Published: 19 December 2007

\begin{abstract}
An eddying global model is used to study the characteristics of the Antarctic Circumpolar Current (ACC) in a streamline-following framework. Previous model-based estimates of the meridional circulation were calculated using zonal averages: this method leads to a counter-intuitive poleward circulation of the less dense waters, and underestimates the eddy effects. We show that on the contrary, the upper ocean circulation across streamlines agrees with the theoretical view: an equatorward mean flow partially cancelled by a poleward eddy mass flux. Two model simulations, in which the buoyancy forcing above the ACC changes from positive to negative, suggest that the relationship between the residual meridional circulation and the surface buoyancy flux is not as straightforward as assumed by the simplest theoretical models: the sign of the residual circulation cannot be inferred from the surface buoyancy forcing only. Among the other processes that likely play a part in setting the meridional circulation, our model results emphasize the complex three-dimensional structure of the ACC (probably not well accounted for in streamline-averaged, two-dimensional models) and the distinct role of temperature and salinity in the definition of the density field. Heat and salt transports by the time-mean flow are important even across time-mean streamlines. Heat and salt are balanced in the ACC, the model drift being small, but the nonlinearity of the equation of state cannot be ignored in the density balance.
\end{abstract}

Correspondence to: A. M. Treguier

(treguier@ifremer.fr)

\section{Introduction}

The meridional circulation of the Antarctic Circumpolar Current (ACC) is a key component of the global thermohaline circulation. It is believed to be comprised of two cells (Rintoul et al., 2001). The upper one involves upwelling of deep waters south of the ACC, northward transport in the Ekman layer and transformation into less dense waters (notably Antarctic intermediate water, AAIW). The second cell transforms upwelled deep waters into denser Antarctic Bottom Water (AABW) along the coast of Antarctica. The amplitude of the overturning cells is not well known for a number of reasons. Firstly, air-sea fluxes are subject to large uncertainties, especially over the Southern Ocean. Secondly, data coverage is sparse: inverse models give some indication of transport at $30^{\circ} \mathrm{S}$, but no circumpolar full-depth hydrographic section is available south of that latitude, and estimates at $30^{\circ} \mathrm{S}$ vary considerably. Finally, mesoscale eddy fluxes are believed to play an important role in the meridional circulation, and measurements of those fluxes are available at only a few locations.

Estimates from numerical models often provide guidance where observations are sparse. However, the usual measure of the meridional circulation in models, the zonally averaged, depth-integrated meridional transport, is of little help in the ACC. The overturning in depth coordinates is dominated by the so-called "Deacon cell", with a near-surface flow equal to the Ekman transport (about $30 \mathrm{~Sv}$ ) and a deep return flow below $2000 \mathrm{~m}$. This circulation was at first a puzzle, because there is no physical mechanism that could explain a direct sinking of water from the surface to $2000 \mathrm{~m}$ near $40^{\circ} \mathrm{S}$ (there is no deep convection in that region). Döös and Webb (1994),

Published by Copernicus Publications on behalf of the European Geosciences Union. 
Table 1. Grid type and resolution of various models referenced in this paper. The name of the model is given with the resolution most often quoted in the literature. The grid type refers to the southern hemisphere (OCCAM and ORCA025 have rotated or bipolar grids in the northern hemisphere). The Mercator grid is isotropic, i.e., $d y$ is refined as $d x$ decreases poleward.

\begin{tabular}{llcl}
\hline Model & Grid type & $d y$ at $60^{\circ} \mathrm{S}$ & Reference in this paper \\
\hline POCM 1/4 & lon,lat & $44 \mathrm{~km}$ & Jayne and Marotzke (2002) \\
FRAM $1 / 3^{\circ}$ & lon,lat & $28 \mathrm{~km}$ & Döös and Webb (1994) \\
OCCAM 1/4 & lon,lat & $28 \mathrm{~km}$ & Lee and Coward, 2003 \\
POP $1 / 6^{\circ}$ & Mercator & $16 \mathrm{~km}$ & Olbers and Ivchenko (2001) \\
ORCA025 1/4 & Mercator & $14 \mathrm{~km}$ & Barnier et al. (2006) \\
MESO $1 / 6^{\circ}$ & Mercator & $9 \mathrm{~km}$ & Hallberg and Gnanadesikan (2006) \\
OCCAM $1 / 12^{\circ}$ & lon,lat & $9 \mathrm{~km}$ & Lee et al. (2007) \\
POP $1 / 10^{\circ}$ & Mercator & $6 \mathrm{~km}$ & Maltrud and McClean (2005) \\
\hline
\end{tabular}

using the FRAM model, showed that this cell is an artifact of zonal averaging, and involves branches of equatorward and poleward flow at the same depth but slightly different densities that cancel out in the zonal average. It is thus necessary to consider the meridional circulation in density coordinates to study that part of the meridional overturning circulation that is relevant to water-mass transformation.

As an alternative, following the analogy with the Ferrell cells in the atmosphere, it is possible to calculate a residual mean streamfunction (Mc Intosh and Mc Dougall, 1996). The definition most often used for the residual meridional velocity is

$v_{\mathrm{Res}}=\bar{v}-\left(\frac{\overline{v^{\prime} \sigma^{\prime}}}{\overline{\sigma_{z}}}\right)_{z}$

where $v$ is the meridional velocity, $\sigma$ the potential density, the overbar represents an average (zonally and in time), prime represents the deviation about this average, and the subscript $z$ represents a vertical derivative. Mc Intosh and Mc Dougall (1996) show that to second order in the perturbation, this definition of the residual circulation is equal to the circulation averaged in density coordinates. However, the two definitions differ greatly in the surface mixed layer, because the vertical derivative of $\sigma$ appearing at the denominator in (1) vanishes. To complicate the picture further, both Döös and Webb (1994) and McIntosh and McDougall (1996) point out that in realistic models, the intensity of the circulation cells depends on the choice of density coordinates. Döös and Webb (1994) present circulations averaged at constant $\sigma_{0}$ and $\sigma_{3}$ (potential density referenced to the surface and $3000 \mathrm{~m}$, respectively) and Mc Intosh and Mc Dougall (1996) use neutral density. As a result of those different methods, no consistent picture has emerged despite the publication of many meridional circulations from models (among others, Döös and Webb, 1994; Mc Intosh and Mc Dougall, 1996; Olbers and Ivchenko, 2001; Lee and Coward, 2003; Lee et al. 2007; Hallberg and Gnanadesikan, 2006).
The first aim of this study is to present a more coherent and complete picture of the meridional circulation in the ACC, by using a global model which brings together for the first time three important features: 1) an eddy-permitting model with an isotropic grid size of $14 \mathrm{~km}$ at $60^{\circ} \mathrm{S}$ (see Table 1); 2) a coupled ocean-ice model with very well balanced, stateof-the-art atmospheric forcing; and 3) a long integration (44 years) allowing the ocean to adjust more thoroughly than in many previous studies with eddying models.

An eddying model is necessary because the residual mean meridional circulation has an eddy component. This appears clearly in (1), and the same is true in the isopycnal framework: in the latter case the transport is integrated over the instantaneous isopycnal thicknesses $h$, so that

$v_{\operatorname{Res}}=\bar{v}+\frac{\overline{v^{\prime} h^{\prime}}}{\bar{h}}=\bar{v}+v^{*}$

where $v^{*}$ is the "bolus" velocity, for which a parameterization has been proposed by Gent et al. (1995) who pointed out its potential importance in the ACC. Indeed, in a zonal geometry and in the absence of diabatic effects, the eddy $v^{*}$ cancels the mean $\bar{v}$; this is the well-known non-acceleration theorem (Andrews and McIntyre, 1976). Danabasoglu et al. (1994) first demonstrated this cancellation using the Gent et al. (1995) parameterization in a low resolution global model. In the following years the eddy contribution has been calculated directly in a number of high resolution models. Olbers and Ivchenko (2001) use (1) in the POP model and find the eddy contribution to be dominant at a depth of 2000-3000 m, with an amplitude of $25 \mathrm{~Sv}$. Lee and Coward (2003) find a weaker eddy contribution of $6 \mathrm{~Sv}$ in the OCCAM model using (2), with poleward eddy flow up to the surface. The difference between the two models estimates still exists when using the same definition (1), so that Lee and Coward (2003) suggest that it may be a result of the different spatial resolution of the two models (Table 1). The spread among estimates from models seems as large for the eddy contribution as it is for the total circulation itself. 
In recent years, a number of attempts have been made to build semi-analytic models of the meridional circulation of the ACC. Marshall (1997) proposed an idealized zonal averaged model, relating the strength of the meridional residual streamfunction beneath the mixed layer $h_{m}$ to the surface density forcing $D$, such that

$\psi_{\operatorname{Res}}\left(-h_{m}\right)=-\int_{-H}^{-h_{m}} v_{\operatorname{Res}}=\frac{D}{\overline{\sigma_{y}}}$

where $\psi_{\text {Res }}$ is the meridional residual streamfunction, $H$ is the ocean depth and $\sigma_{y}$ is the meridional potential density gradient in the mixed layer. (3) is derived from an equation for potential density, assuming a statistically steady state and no diabatic effects in the interior (see also Karsten and Marshall, 2002). Marshall (1997) illustrates (3) by two solutions, one with no surface density flux and zero meridional circulation (exact cancellation of eddy and mean) and one with a cooling density flux that gives a net poleward meridional circulation in the upper layers. It is important to note that with the realistic geometry of the ACC the above model holds only when integrated following time-mean streamlines; in the zonal average one needs to take into account the correlations $\overline{v \sigma}$ resulting from the permanent meridional excursions of the ACC ("standing eddies"). A further remark is that $D$ in (3) should include the lateral diabatic eddy fluxes in the mixed layer (Radko and Marshall, 2003). Karsten and Marshall (2002) use Southern Ocean observations to calculate the terms in (3). They estimate separately the mean and eddy component of the residual streamfunction $\psi_{\text {Res }}$. The mean streamfunction at the mixed layer base is taken to be equal to the Ekman transport:

$\bar{\psi}=-\frac{\bar{\tau}}{\rho_{0} f}$,

where $\tau$ is the wind stress, $\rho_{0}$ the reference density and $f$ the Coriolis frequency. The eddy streamfunction is parameterized using the Gent and McWilliams formulation:

$\psi^{*}=\frac{\overline{v^{\prime} \sigma^{\prime}}}{\overline{\sigma_{z}}}=-\kappa \frac{\overline{\sigma_{y}}}{\overline{\sigma_{z}}}$,

where $\kappa$ is a mixing coefficient, which Karsten and Marshall (2002) evaluate using observed sea surface height variability. The mean transport given by (4) is equatorward in the upper layers in the whole Southern Ocean. Because the slope of isopycnals does not change sign, the eddy transport given by (5) is poleward. The residual circulation is thus the sum of two opposite contributions of the same order of magnitude, and the sum is very dependent on the choice of $\kappa$ in (5). Karsten and Marshall (2002) suggest that the eddies only partially compensate the mean in the southern part of the ACC, with a residual transport of $10 \mathrm{~Sv}$ equatorward, and that the eddies dominate the Ekman transport in the northern part, leading to a residual mean poleward flow of $10 \mathrm{~Sv}$. Analytical models based on (3)-(5) have been derived to explore the influence of various forcings and boundary conditions (Marshall and Radko, 2003; Olbers and Visbeck, 2005). Olbers and Visbeck (2005) extend the model to take into account diabatic effects at the base of the surface mixed layer.

To our knowledge, the elegant conceptual model described in Eqs. (4)-(5) has never been tested in a realistic eddy resolving model. There have been only two attempts at calculating mean and eddy transports across streamlines. Ivchenko et al. (1996) used the FRAM model; they performed an analysis of the momentum balance across streamlines but did not consider the surface circulation in detail. Lee and Coward (2003) obtain puzzling results with the OCCAM $1 / 4^{\circ}$ model: they find that the time-mean meridional circulation dominates in the upper layers, and that the eddy contribution is important only at depth (1500 to $3000 \mathrm{~m})$. Neither study has attempted to relate the meridional circulation to the model buoyancy fluxes. The eddy transports being dependent on model resolution, it is important to perform new calculations of the meridional circulation across ACC streamlines using higher resolution models.

The aim of our study is to determine the upper ocean residual circulation in the ACC belt using a streamline framework, and to document the extent of the cancellation between the eddy and mean flow. Our analysis concentrates on the region of truly circumpolar flow, bounded by the northernmost and southernmost lines of constant barotropic tranport that go through the Drake Passage. Following Ivchenko et al. (1996) we call this area the "ACC belt". We concentrate on the upper meridional cell, also called the "Diabatic Deacon Cell" by Speer et al. (2000). We will try to relate this upper residual circulation to the buoyancy forcing as in (3). We calculate the residual circulation in two solutions of the same model, but with different atmospheric forcings resulting in a different sign of the buoyancy flux over the ACC. We also calculate the balances of depth-integrated heat and salt and discuss the possibility of deriving a similar integrated balance for density.

\section{The numerical experiment}

The global ORCA025 model is described in Barnier et al. (2006). This model configuration uses a global tripolar grid with $1442 \times 1021$ grid points and 46 vertical levels. Vertical grid spacing is finer near the surface $(6 \mathrm{~m})$ and increases with depth to $250 \mathrm{~m}$ at the bottom. The grid is completely isotropic in the Southern hemisphere; horizontal resolution is $27.75 \mathrm{~km}$ at the equator, $13.8 \mathrm{~km}$ at $60^{\circ} \mathrm{N}$, and gets to $7 \mathrm{~km}$ in the Weddell and Ross Seas (Table 1). Numerical details are found in Barnier et al. (2006). The ocean-ice code is based on the NEMO framework (Madec, 2007) version 1.9; it uses a partial step representation of the bottom topography and an improved advection scheme for momentum. Parameterizations include a laplacian mixing of temperature and salinity along isopycnals, a horizontal biharmonic viscosity, 


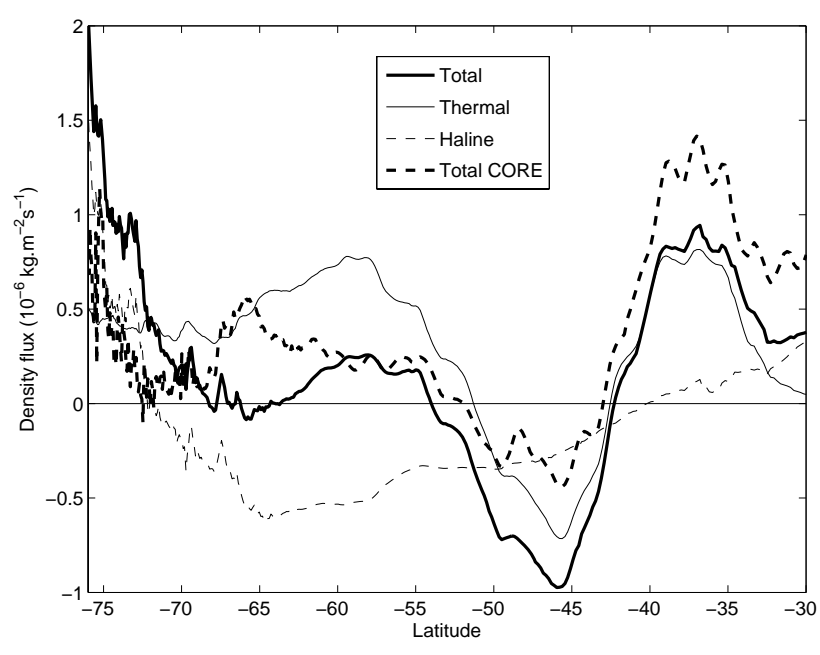

Fig. 1. Zonal average of the surface density flux (thick continuous line), and the thermal and haline contributions (thin lines) for the reference experiment. The density flux of the CORE sensitivity experiment is indicated by the heavy dashed line. Positive values mean density gain for the ocean (buoyancy loss).

and a turbulence closure scheme (TKE) for vertical mixing. The bathymetry is derived from the 2-min resolution Etopo2 bathymetry file of NGDC (National Geophysical Data Center), merged with the BEDMAP data (Lythe and Vaughan, 2001) beyond $72^{\circ} \mathrm{S}$ in the Antarctic.

The reference experiment considered in the present paper differs from the one of Barnier et al. (2006) because a different forcing dataset is used. The experiment is interannual and runs from 1958 to 2002 with no spin-up (the initial condition is the Levitus 1998 climatology). The forcing dataset is a blend of data from various origins and different frequencies (Brodeau, 2007). Precipitation and radiation are from the CORE dataset assembled by W. Large (Large and Yeager, 2004), at monthly and daily frequency respectively. Precipitation and radiation are based on satellite observations when available; a climatology of the same satellite dataset is used for the early years. Air temperature, humidity and wind speed are six-hourly fields from the ECMWF reanalysis ERA40. Turbulent fluxes (wind stress, latent and sensible heat flux) are estimated using the CORE bulk formulae (Large and Yeager, 2004). To avoid an excessive model drift we add a relaxation to the Levitus climatology of sea surface salinity. The coefficient $(0.167 \mathrm{~m} /$ day $)$ amounts to a decay time of 60 days for $10 \mathrm{~m}$ of water depth; under the ice cover restoring is 5-times stronger. We also add extra restoring at the exit of the Red Sea and Mediterranean Sea because those overflows are not adequately represented at that model resolution. A complete description of the experiment is found in a report (Molines et al., 2006). We have chosen to study a 10 year period from 1991 to 2000 (10 years is a sufficient period to compute eddy statistics; we prefer a period near the end of the experiment so that the model drift is smaller). Unless specified otherwise, "mean" quantities in this paper will refer to the 1991-2000 time-mean.

We also use a sensitivity experiment with the CORE "normal year" climatological forcing (Large and Yeager, 2004). This forcing field is based on NCEP rather than ERA40 atmospheric variables. The normal year is constructed by using the high frequency variability of 1992, with corrections so as to obtain annual mean fluxes close to the 1979-2000 climatology. There is no relaxation to climatological sea surface salinity under the sea ice in the CORE experiment, and the vertical mixing parameterization differs. The CORE sensitivity experiment is shorter ( 10 years); years 8 to 10 are used to calculate statistics.

It is always difficult to obtain a stable solution with a global ocean model forced by a prescribed atmosphere, because the forcings usually have a nonzero average over the globe. Trying to balance the fluxes using observed sea surface temperature, as done by Large and Yeager (2004), is useful but does not prevent model drift. This is because the model fluxes during the integration are calculated with the model sea surface temperature which differs from the observed. The forcing fields for the long ORCA025 experiment have been tested using low resolution model experiments (Brodeau, 2007) and the precipitation has been adjusted in order to minimize the model drift. The experiment is run during 47 years without any "on-line" correction of the sea surface height (SSH). During the 10 year period considered here, the global SSH increases by $11 \mathrm{~cm}$ due to a net sum of evaporation, precipitation and runoff of $0.12 \mathrm{~Sv}$. This is a small flux imbalance compared, for example, with the total runoff $(1.26 \mathrm{~Sv})$. The global mean temperature decreases by $0.011^{\circ} \mathrm{C}$ due to a cooling of $0.09 \mathrm{PW}$ (an average of $0.25 \mathrm{~W} \mathrm{~m}^{-2}$ ) due to the direct surface heat flux, and a cooling of $0.06 \mathrm{PW}\left(0.18 \mathrm{~W} \mathrm{~m}^{-2}\right)$ due to the heat carried by the water exchanged through the free surface.

Regarding the ocean circulation, Barnier et al. (2006) show that ORCA025 represents the main ocean currents, the sea surface height and the surface eddy kinetic energy remarkably well. Indeed in some areas ORCA025 compares favorably with higher resolution models such as POP $1 / 10^{\circ}$ (Maltrud and McClean, 2005). The good representation of the major fronts, together with the length of the reference experiment which ensures a weak drift, make it the most suitable for our investigation of the residual circulation in the upper layers of the ACC.

The heat and freshwater fluxes in the Southern Ocean are subject to large uncertainties. It is useful to examine the zonal average of the density fluxes in our model for comparison with previously published estimates. Figure 1 shows fluxes into the ocean, including ice-ocean fluxes and relaxation to climatological sea surface salinity (SSS). This latter term is smaller than the 'true' freshwater flux (sum of evaporation, precipitation and runoff) in most of the domain, except under ice. 
In the southern part of the domain (south of $70^{\circ} \mathrm{S}$ ), the model surface waters are made denser by cooling and by an input of salt. This input is partially due to brine rejection during ice formation, followed by ice export to the north; however a large contribution also comes from SSS relaxation under ice, as shown by the difference between the reference experiment and the CORE experiment (Fig. 1). In the latitude band $70^{\circ} \mathrm{S}$ to $53^{\circ} \mathrm{S}$, the density flux is small (reference case) or positive (CORE case). This agrees with a similar curve from a low resolution isopycnic model (Marsh et al., 2000, their Fig. 5), but many authors assume a net density loss in that latitude range (the density flux often used in idealized models, e.g, Marshall and Radko, 2003, is $\left.-2 \times 10^{-7} \mathrm{~kg} \mathrm{~m}^{2} \mathrm{~s}^{-1}\right)$. No reliable estimate of the density flux can be made from observations in that region, because it results of a near cancellation between cooling and freshening, both of which are known only within large error bars. It is even unclear whether the heat flux between 55 and $65^{\circ} \mathrm{S}$ should be negative or positive. There is cooling in both our experiments (in the CORE case with NCEP air temperature as well as in the reference case with ERA40 temperature), while Speer et al. (2000) argue for a heating in that latitude band, based on the COADS dataset.

Farther north between $53^{\circ} \mathrm{S}$ to $43^{\circ} \mathrm{S}$, the density flux is negative due to the combined effect of freshening and warming. The warming is linked to a strong heat gain in the Malvinas Current and south of the Agulhas retroflection region, in the Atlantic and Indian sectors. Although dismissed as a spurious feature by Gallego et al. (2004), such a warming shows up in a large number of datasets (Wacongne et al., 2007 ${ }^{1}$ ). It corresponds to an increase of the global ocean meridional heat transport (MHT) in that latitude band. This change in the slope of the global MHT curve is found in transports derived from atmospheric energy balances (Trenberth et al., 2001, their Fig. 13a and b) as well as in many high resolution global ocean model solutions (Maltrud and McClean, 2005; Lee et al., 2007; Meijers et al., 2007). Further to the north in the subtropical region, the density flux is again positive because of a large heat loss and evaporation in the Brazil Current and in the Indian sector (in the Agulhas retroflection and its downstream extension). Generally, the surface fluxes in the Southern Ocean in the ORCA025 model, as well as the heat and freshwater transports, are within the admittedly large uncertainties of other published estimates.

\section{Flow characteristics along the ACC belt}

In this section we describe the ACC region in the reference experiment. The CORE sensitivity run is mentioned only when the results are significantly different. At the beginning of the reference run, the transport through Drake Pas-

\footnotetext{
${ }^{1}$ Wacongne, S., Speer, K., Lumpkin, R., and Sadoulet, V.: Warm water formation in the midst of the Southern Ocean, J. Mar. Res., submitted, 2007
}

sage undergoes an adjustment: it decreases from $150 \mathrm{~Sv}$ to $115 \mathrm{~Sv}$ from 1958 to 1970 . The transport remains stable afterwards, with a 1991-2000 time average of $117 \mathrm{~Sv}$. Figure 2 shows two extreme contours of the barotropic streamfunction going through Drake passage. We also indicate on this figure the Subantarctic Front, calculated as the southernmost extent of the salinity minimum, and the Polar Front, calculated as the northernmost extent of the temperature minimum (calculated between $40 \mathrm{~m}$ and $400 \mathrm{~m}$ ). The position of those fronts agrees overall with the estimates based on hydrographic sections (Orsi et al., 1995) or sea surface height variability (Sokolov and Rintoul, 2007). The temperature minimum south of the polar front is simulated in the model, as shown by a section corresponding to the WOCE SR3 line between Tasmania and Antarctica (Fig. 3). Data from a january 1995 cruise (Sokolov and Rintoul, 2002) compare well with model results averaged during the same month. The temperature minimum in the model is found slightly higher in the water column than observed, especially at its northern end. The minimum temperature is warmer than observed (in the data, there is a significant thickness of water colder than $0^{\circ} \mathrm{C}$ at $60^{\circ} \mathrm{S}$, which is not the case in the model). Despite those discrepancies the model representation of the temperature minimum is very satisfactory compared with previous experiments, such as the one described in Barnier et al (2006), where it was much too close to the surface. The improvement has been brought about by a modification of the vertical mixing scheme to allow more penetration of the turbulent eddy kinetic energy (G. Madec, personal communication). The lower panel in Fig. 3 shows the zonal velocity. The model has alternate bands of westward and eastward flow (about ten of them) in close agreement with the ten jets identified by Sokolov and Rintoul (2007) from sea surface height. Indeed, a time-latitude plot of the meridional gradient of sea surface height (not shown) looks qualitatively similar to the observations (Sokolov and Rintoul, 2007; their Fig. 1). This confirms that the model resolution is sufficient to capture the scale of the main eddies and jets of the ACC.

We have chosen to define the ACC belt as the region bounded by two contours of barotropic streamfunction: the $7 \mathrm{~Sv}$ contour to the north and the $117 \mathrm{~Sv}$ contour to the south (black contours in Fig. 2). A small amount of smoothing has been performed before calculating the contours, but most of their complex structure has been retained. These contours define a more realistic path than the smoothed contours derived by Karsten and Marshall (2002) from observations. The excursion of the northern boundary following the Malvinas Current is faithfully represented in ORCA025 (compare Fig. 2 with the geostrophic streamlines in Karsten and Marshall's Fig. 1). This level of detail is necessary to calculate consistent balances involving transport and surface fluxes in this high resolution model. To estimate the meridional structure within the ACC belt we use 12 contours of barotropic streamfunction (every $10 \mathrm{~Sv}$ from $7 \mathrm{~Sv}$ to $117 \mathrm{~Sv}$ ). In order to have a complete view of the meridional circulation 

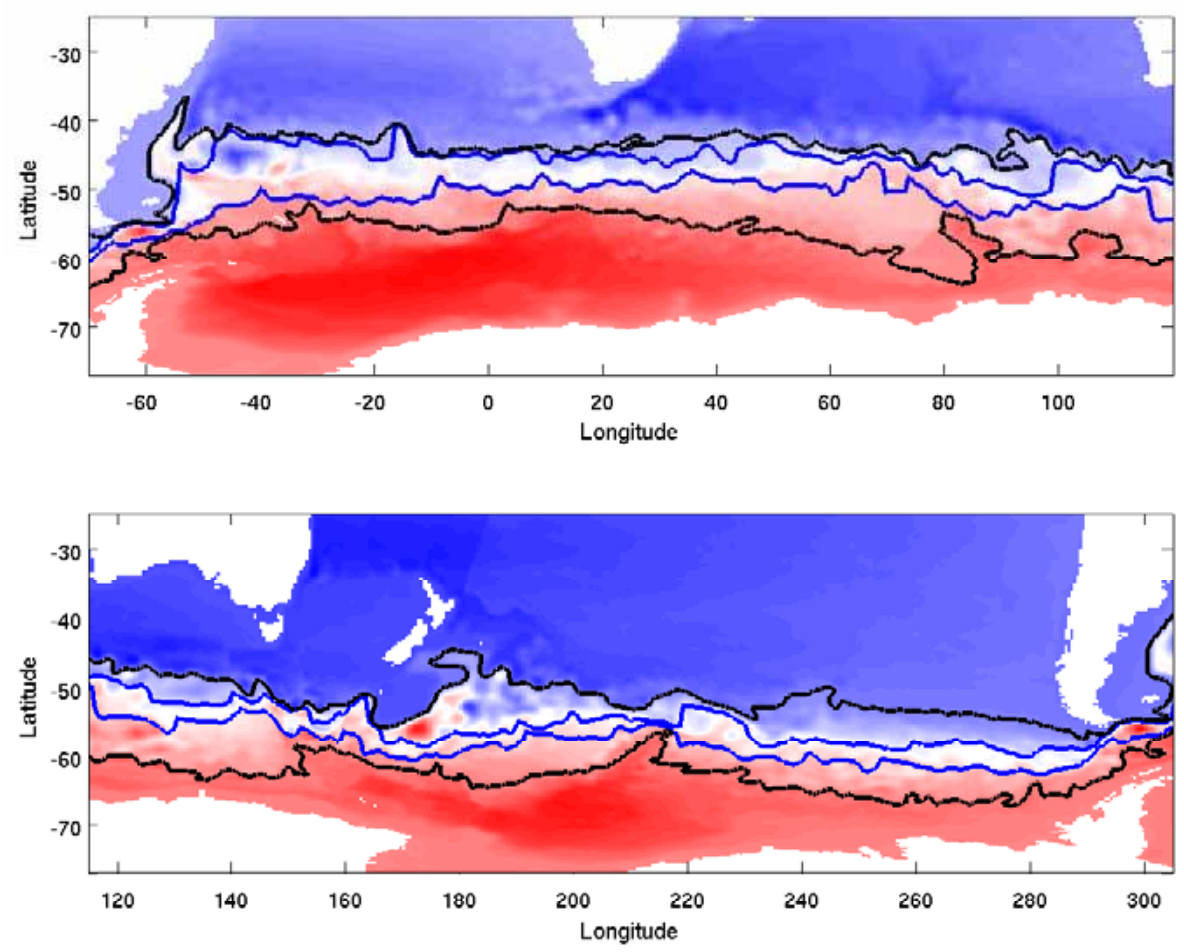

Fig. 2. Time mean barotropic streamfunction (color). The black contours ( $7 \mathrm{~Sv}$ and $117 \mathrm{~Sv}$ ) represent the limits of the ACC belt (circulation that flows through Drake Passage). The Subantarctic Front (north) and the Polar Front (south) are indicated in blue (see text for definition).

in the Southern Ocean, it is important to sample the region south of the ACC belt, because most of the upwelling occurs there. Karsten and Marshall (2002) used geostrophic streamlines and avoided closed contours by heavy smoothing and restricting their domain to $70^{\circ} \mathrm{S}$. Our high resolution model has its southern boundary at $80^{\circ} \mathrm{S}$ and has well defined Ross and Weddell gyres, with many closed contours of barotropic streamfunction: using dynamics to define circumpolar contours south of the ACC belt is impossible. We have thus simply defined 8 additional lines by interpolating linearly between the ACC belt southern boundary (117 Sv contour) and the coast of Antarctica.

We have chosen barotropic streamfunction to define our streamlines because we prefer paths that are valid at all depths, in a vertically averaged view. At an early stage of this study we have also considered contours of sea surface height (as Karsten and Marshall, 2002) and the results were not significantly different. Using Bernouilli potential contours as Polton and Marshall (2007) would complicate the analysis since those contours would need to be defined differently on different isopycnals.

To investigate the meridional structure of the ACC, we present a few quantities averaged along those 20 lines. The sections are plotted as a function of the mean latitude of each line in Fig. 4. The top panels show the mean and rms alongstream velocity. The velocities are quite small, even though the surface kinetic energy of the model is similar to satellite observations (Barnier et al., 2006) and the instantaneous velocities in the jets are large (note for example the maximum eastward velocity of $0.65 \mathrm{~m} / \mathrm{s}$ along the SR3 section in Fig. 3). The streamline-averaged velocities are reduced because of meandering, and because the lines pass through regions of high and low velocities. There is no complex structure in these sections: velocities increase from south to north without showing multiple maxima. This is because we perform averaging along lines that are fixed in time. Meandering across those lines obscures the multiple jet structure, since the meridional scale of the meanders is not small compared to the spacing between jets (especially as the jets come close together at choke points, like in the Drake Passage). The bottom panels in Fig. 4 show salinity and temperature profiles, as well as three isopycnal surfaces $\left(\sigma_{0}=27\right.$, 27.5 , and $27.7 \mathrm{~kg} \mathrm{~m}^{-3}$ ). The isopycnals cross the isotherms at a sharp angle resulting in large gradients of temperature and salinity along isopycnals. The salinity minimum corresponding to Antarctic Intermediate Water appears clearly in the salinity section.

Let us now consider the forcings averaged along streamlines. The Ekman transport is shown in Fig. 5, bottom panel. It reaches a maximum of $28.7 \mathrm{~Sv}$ near $50^{\circ} \mathrm{S}$ for the reference 

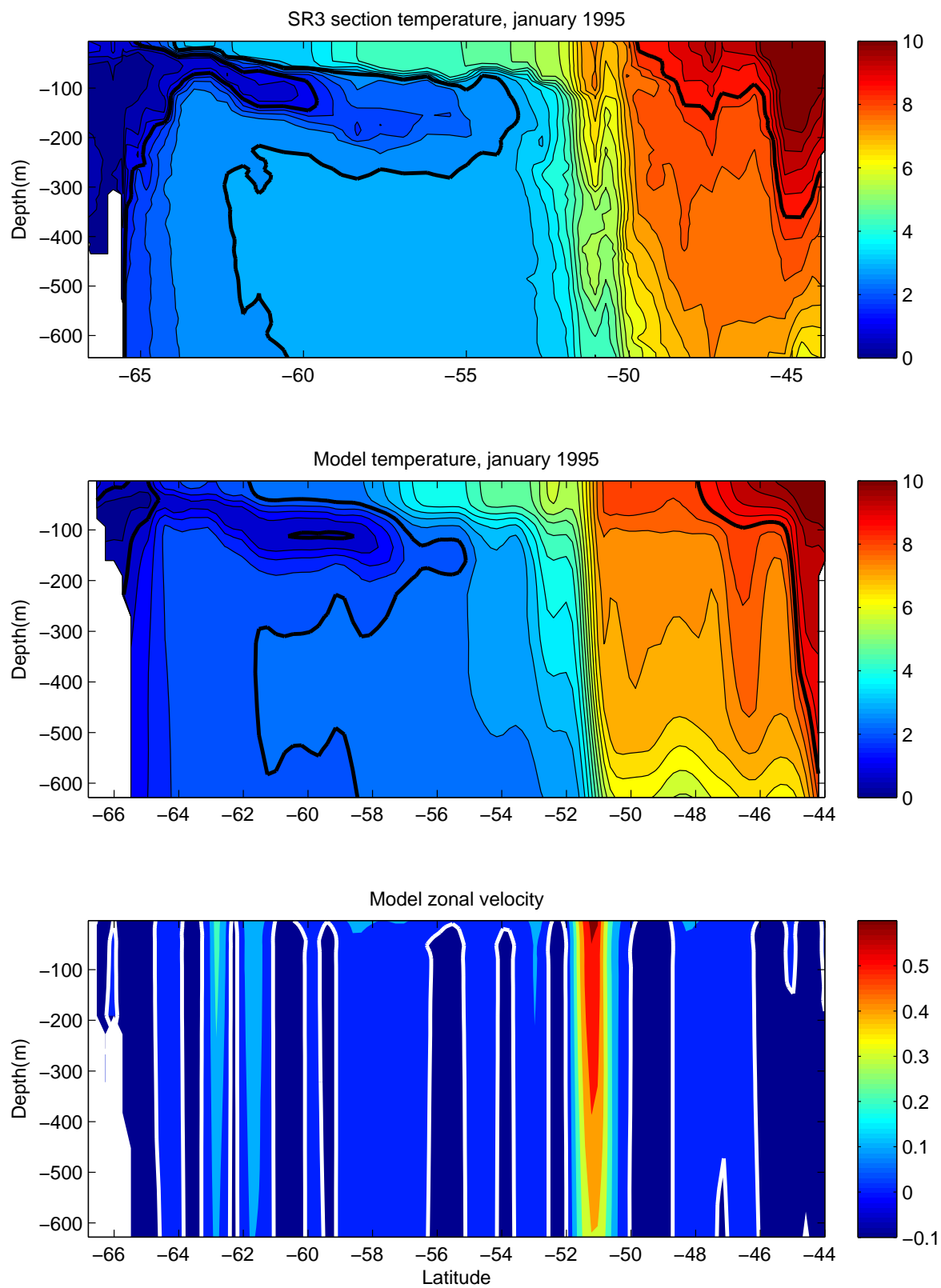

Fig. 3. Observations and model results along the WOCE SR3 section. Top panel: observed potential temperature (January 1995). Temperatures of 0,2 and $10^{\circ} \mathrm{C}$ are indicated in bold. Middle panel: model potential temperature averaged for January 1995. Bottom panel: zonal velocities $(\mathrm{m} / \mathrm{s})$. The zero contour is underlined in white.

case and 25.4 Sv for the CORE case. The streamline average is not very different from the zonal average. Two thirds of the Ekman transport divergence (driving the upwelling) occurs south of the ACC belt. The density flux is shown in Fig. 5, top panel. For the reference experiment, the streamline average results in a negative density forcing: the mean between $65^{\circ} \mathrm{S}$ and $50^{\circ} \mathrm{S}$ is $-0.23 \times 10^{-6} \mathrm{~kg} \mathrm{~m}^{2} \mathrm{~s}^{-1}$, close to the value used by Marshall and Radko (2003). Over the ACC belt (north of the limit indicated on the graph) there is a sharp contrast between the density flux for the reference experiment (buoyancy gain) and the CORE experiment (buoyancy loss). If the simplified Eq. (3) holds in the model, we would expect a different sign of the residual meridional circulation in the two cases. Using (3) and the model surface density gradient we find $\psi_{\text {Res }}=3.4 \mathrm{~Sv}$ for the reference case, and $\psi_{\text {Res }}=-1 \mathrm{~Sv}$ for the CORE experiment. These estimates do not agree with a direct calculation of $\psi_{\text {Res }}$ as we will see in the following section. Note that we are not able to calculate 

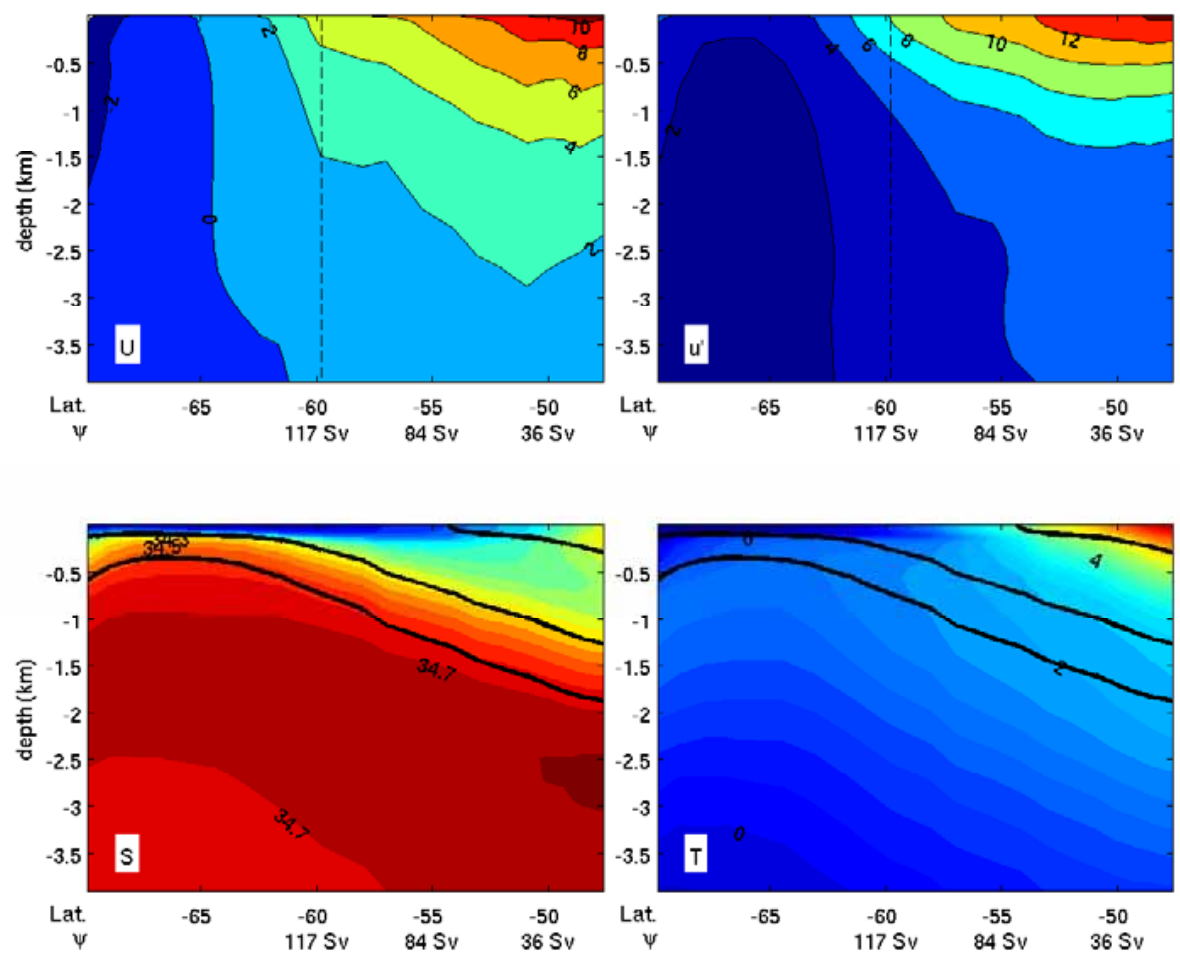

Fig. 4. Sections averaged following streamlines of the ACC, plotted as a function of the mean latitude of each streamline. In the two top panels the vertical dashed line indicates the southern limit of the ACC belt. Top left: along-stream velocity. Top-right: rms velocity. Bottom left: contours of salinity (contour interval 0.1 PSU). Three isopycnals defined by $\sigma_{0}=27,27.5$ and $27.7 \mathrm{~kg} \mathrm{~m}^{-3}$ are indicated by bold lines. Bottom right: contours of temperature (contour interval $0.5^{\circ} \mathrm{C}$ ) with the same three isopycnals superimposed.

accurately the contribution of lateral diabatic eddy fluxes in the mixed layer from our model output, and thus consider only the contribution from surface buoyancy forcing in (3).

Before moving on to the meridional circulation, it is important to note that the characteristics of the ACC vary strongly along its path. As discussed below, it is essential to take these along-stream variations of the ACC into account to understand the Southern Ocean overturning circulation and its relationship to surface forcing. Because eddy fluxes and upper ocean stratification are two important variables in determining the nature of the overturning circulation, we show the eddy kinetic energy (EKE) and mixed layer depth averaged over the ACC belt, both in the model and in observations. The generally good agreement between the model and observations increases our confidence that the model captures ocean physics sufficiently well to provide insights into the dynamics of the residual mean circulation.

The surface EKE varies along the path of the ACC by more than a factor of 10 , in both model and observations (Fig. 6). The observed EKE is computed from satellite altimetry (Ducet et al., 2000). Peaks of EKE are observed in the Agulhas $\left(25^{\circ} \mathrm{E}\right)$, near Crozet $\left(60^{\circ} \mathrm{E}\right)$, downstream of the Kerguelen plateau $\left(75-90^{\circ} \mathrm{E}\right)$, south of Tasmania and New Zealand (160 and $\left.175^{\circ} \mathrm{E}\right)$, downstream of Drake passage and in the Brazil-Malvinas confluence zone (around $300^{\circ} \mathrm{E}$ ). The model successfully reproduces high EKE in all those regions, as already noted by Barnier et al. (2006). The CORE experiment has higher EKE than the reference. This may be partly due to stronger winds, but also to the shorter spin-up and/or internannual variability (consider the locally large difference between the two time periods indicated for the reference experiment).As noted by Hallberg and Gnanadesikan (2006), the large variations in EKE along the ACC path, with a spatial pattern clearly related to topography, suggest that instability mechanisms active in the ACC are more complex than simple flat-bottom baroclinic instability. Eddies in the ACC likely depend on horizontal gradients of velocity (barotropic instability) and bottom topography as well as the vertical mean shear (classical baroclinic instability).

Mixed layer depths have been averaged for the month of september for years 1991-2000 of the reference experiment, and year 8 to 10 of the CORE experiment. Climatological mixed layer depths evaluated using a density criterion (de Boyer Montegut et al., 2007) have been averaged over the ACC path for comparison with the model results. The model captures the observed tendency for the mixed layer depth to increase downstream from the Atlantic, from minimum values close to $100 \mathrm{~m}$ to maxima of $400 \mathrm{~m}$ (and even larger, in 

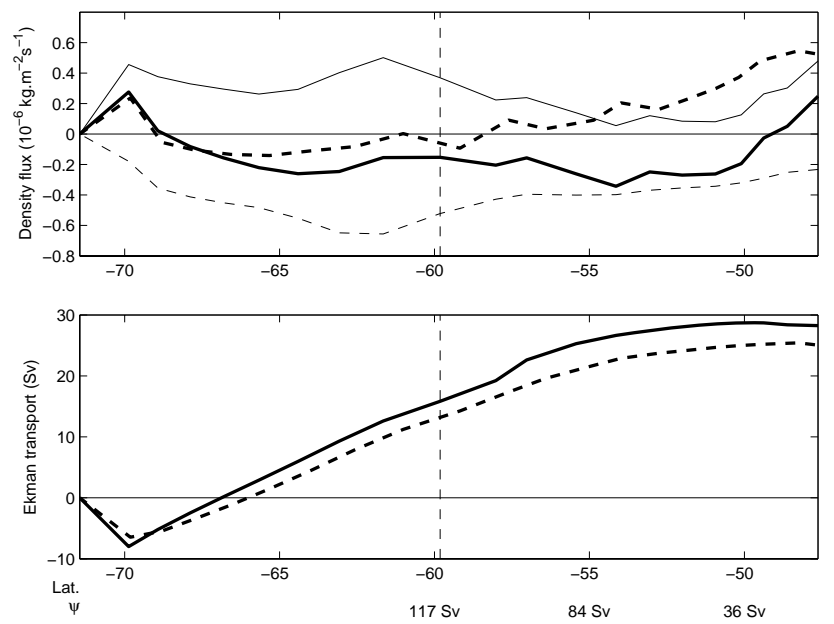

Fig. 5. Top panel: Streamline average of the surface density flux (thick line), and the thermal (thin line) and haline (dashed line) contributions. The density flux of the CORE sensitivity experiment is indicated by the heavy dashed line. Bottom panel: streamlineaveraged Ekman transport for the reference case (solid line) and the CORE experiment (dashed). The vertical dashed line indicates the southern limit of the ACC belt.

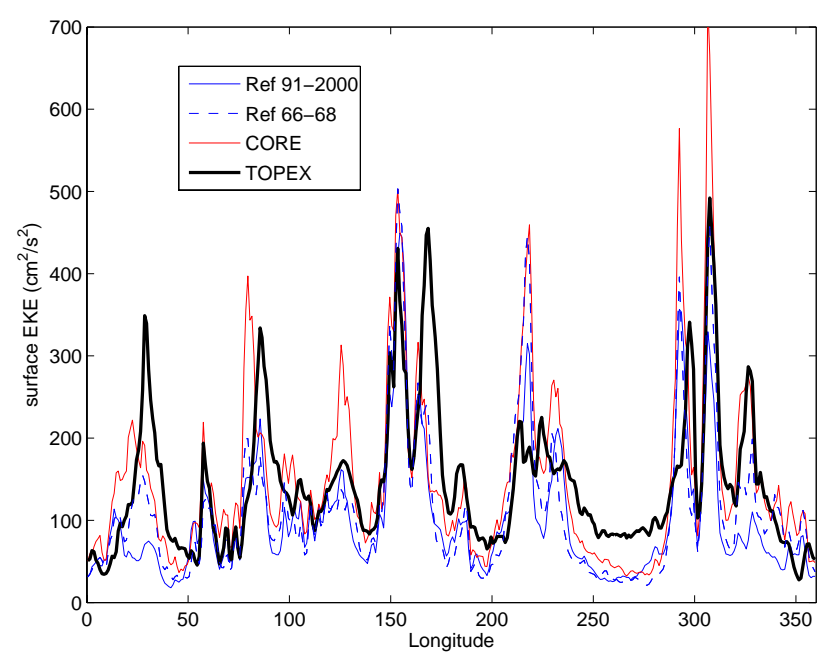

Fig. 6. Surface eddy kinetic energy (EKE) averaged in the ACC belt for each longitude. Data from altimetry, averaged over years 19922002 is indicated by the thick black line. EKE for the reference experiment is shown for two time periods, 1966-1968 (years 8-10 of the experiment) and the reference period 1991-2000.

the model) in the southeast Pacific. The mixed layer in the CORE experiment is systematically shallower than in the reference experiment, with the exception of a few regions of the south Pacific. As discussed below, the difference in the mixed layer depth appears to contribute to the differences in the residual circulation in the two experiments.

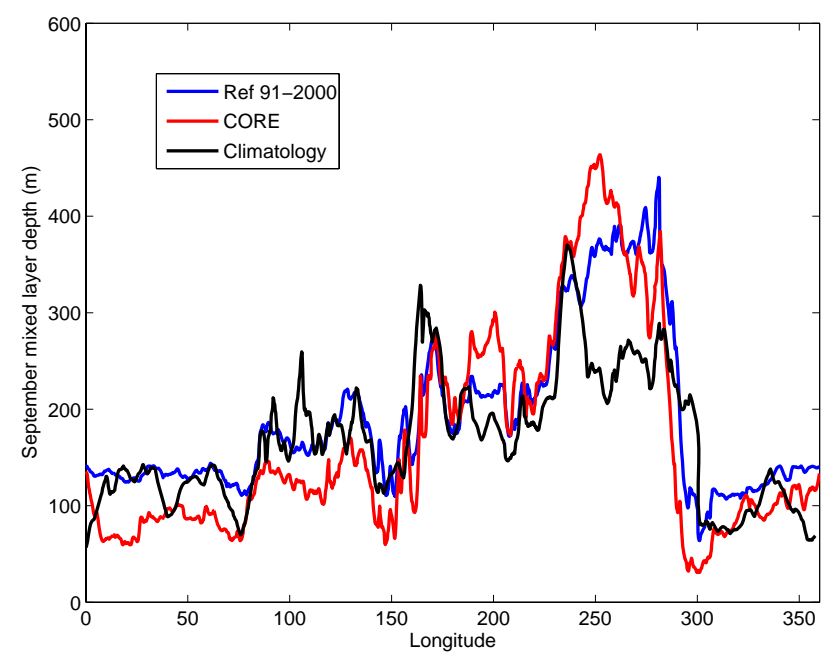

Fig. 7. Average mixed layer depth for the month of september, in the model and in the climatology of de Boyer Montégut et al. (2007), estimated with a density criterion. The model mixed layer depth is estimated as the depth were density is $0.1 \mathrm{~kg} \mathrm{~m}^{-3}$ larger than at the surface.

\section{Meridional circulation in density coordinates}

In this paper, we focus on the meridional circulation integrated in density classes. Formulation (1) is not used here because it breaks down in the surface mixed layer. An alternate formulation proposed by Held and Schneider (1999) and used by Marshall and Radko (2003) does not suffer from this problem. However, it involves the vertical velocity, which tend to be noisy near bottom topography in $z$-coordinate primitive equation models: this could make our results too dependent on the details of the numerical scheme. Rather, we choose the same method as Lee et al. (2007): the horizontal transport is binned in density classes for each 5-day model snapshot and averaged in time; the eddy contribution is then calculated by substracting the time-mean eulerian transport binned in the same density classes using the time-mean density field. This method is robust and ensures that both mean and eddy components are consistent with mass conservation in the model.

Before considering the circulation in the ACC belt, it is useful to show the classical zonally-averaged streamfunction, for reference. We will mainly consider the circulation in $\sigma_{0}$ density classes but we show in Fig. 8 the transport calculated using $\sigma_{2}$ for comparison with a similar figure shown by Lee et al. (2007, their Fig. 5). Note that our sign convention is opposite to theirs. In Fig. 8, there is a bottom cell counterclockwise with a maximum of $14 \mathrm{~Sv}$ near $3500 \mathrm{~m}, 46^{\circ} \mathrm{S}$, but it does not appear to be connected to the surface cell centered at $66^{\circ} \mathrm{S}$. In the OCCAM $1 / 12^{\circ}$ solution of Lee et al., the two cells are connected. The OCCAM picture agrees better with the conventional image of the bottom cell, which results from 


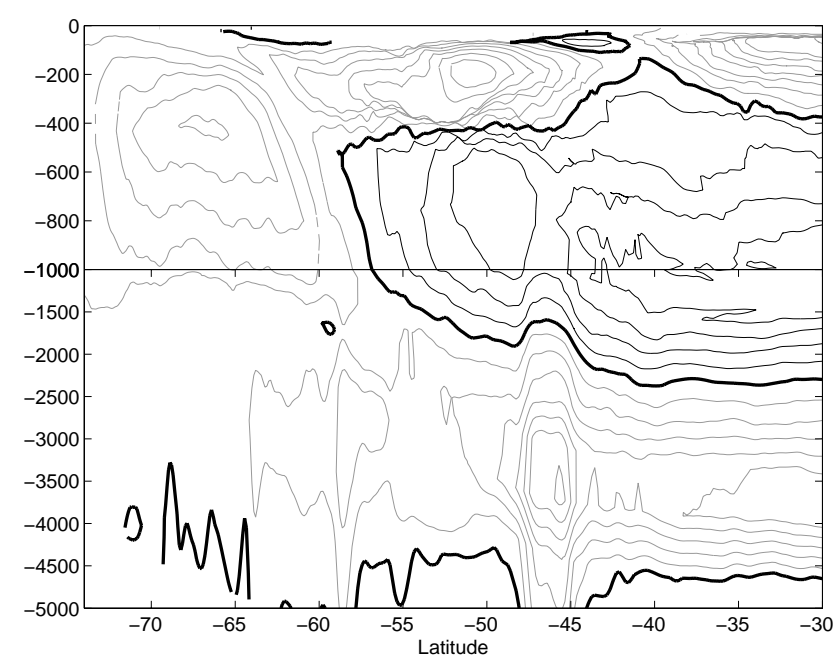

Fig. 8. Zonal-mean meridional transport streamfunction calculated in density space as a function of $\sigma_{2}$, and remapped as a function of depth using the mean depth of the $\sigma_{2}$ surfaces. The top $1000 \mathrm{~m}$ is expanded for visualisation. Positive values (black contours) indicate a clockwise circulation; negative contours are in grey. Contour interval is $2 \mathrm{~Sv}$ and the zero contour is indicated by a thick line.

transformation of Circumpolar Deep Water at the surface into Antarctic Bottom Water (AABW) which sinks to the bottom (see for example the cartoon by Speer et al., 2000). Note however that in fact, the existence and shape of the bottom cell in models is very dependent on a) how close to equilibrium the model is; and b) how the model is forced. Regarding a), Lee et al. (2002) noted that the drift in deep water masses in an early version of OCCAM amounted to a deep cell of more than $20 \mathrm{~Sv}$. The higher resolution model considered in Lee et al. (2007, Fig. 5) is analyzed after a very short spinup period (three years). When we consider our model results after a spin-up period of 8 to 10 years (years 1966 to 1968 of the reference experiment, or years 8 to 10 of the CORE climatological experiment) we also obtain a cell that is continuous from the surface to the bottom, very similar to Lee et al., 2007. During the initial adjustment, the densest waters are flushed equatorwards and the slope of isopycnals decreases, leading to this enhanced bottom cell. Figure 8 shows the reference solution averaged for the 1991-2000 period, after a spin up of 34 years, but the deep waters are still far from equilibrium. The structure and strength of the AABW cell also depend on the way deep waters are forced in the models. In OCCAM $1 / 4^{\circ}$ (Lee et al., 2003) the bottom cell is completely isolated from the surface and there is no surface cell of the same sign. The authors attribute this feature to the lack of an ice model and excessive diapycnal mixing. In the isopycnal model of Hallberg and Gnanadesikan (2006), there is a vigorous bottom cell extending all the way to the surface, but it is forced somewhat artificially by sponge layers near the Antarctic shelf. The mechanisms of AABW formation and the related meridional circulation is a complex issue that will not be considered further here, as we now concentrate on the upper circulation cells.

A surprising feature in Fig. 8 is the counterclockwise cell in the upper $500 \mathrm{~m}$ between $45^{\circ} \mathrm{S}$ and $63^{\circ} \mathrm{S}$. A similar cell appears in OCCAM $1 / 12^{\circ}$ (Lee et al., 2007) which the authors find "unusual" and do not attempt to interpret further. This circulation is also present in the isopycnic model of Hallberg and Gnanadesikan (2006). Those authors show that the cell is limited in its southward extent in low resolution models, but becomes stronger and extends farther south when the model resolution is increased (this is probably why it is absent in the lower resolution OCCAM $1 / 4^{\circ}$ of Lee et al., 2002). In the OCCAM $1 / 12^{\circ}$ model, this cell is entirely due to the time-mean flow (permanent meanders), the transient eddy contribution being small excepted around $45^{\circ} \mathrm{S}$ (Lee et al. 2007, their Fig.5b). Hallberg and Gnanadesikan find that in their model both the time-mean and transient eddies contribute to this cell. Our model results thus confirm those two recent high resolution modelling studies; all three models show that in the range of latitudes of the ACC, the zonallyaveraged transport in density coordinates is poleward near the surface, contrary to what is usually expected for the timemean flow (an equatorward flow driven by the Ekman transport). Furthermore, the contribution of transient eddies is small compared to the mean. The explanation for this counterclockwise cell is the same as the one proposed by Döös and Webb (1994) for the Deacon cell, but this time applied to a calculation in density classes at constant latitude rather than a calculation at fixed depths. At a given latitude light water tends to go poleward, and is returned equatorward as denser water, so that the net result is a poleward transport of the more buoyant water. Summing the transport in density classes, we thus start with more poleward transport in the lighter classes. Because the ACC is highly non-zonal, there are large geostrophic velocities across a latitude line and the effect of those velocity-density correlations overcomes the Ekman transport (especially in high-resolution models where velocities are not excessively smoothed). As we will see, calculating the transport across mean streamlines rather than latitude circles more effectively reveals the physical nature of the meridional overturning in the upper ocean.

The time-mean meridional circulation averaged along streamlines in the ACC belt is shown in Fig. 9. Since our discussion focusses on the upper cell, we now use potential density referenced to the surface $\left(\sigma_{0}\right)$ as a coordinate. The circulation is completely different from the zonally averaged picture. The time-mean surface flow is equatorward over the whole ACC belt, with a transport of the order of the Ekman transport, although slightly smaller: it reaches $18 \mathrm{~Sv}$ at $100 \mathrm{~m}$ depth and $\approx 26 \mathrm{~Sv}$ at $500 \mathrm{~m}$. The time-mean circulation in $\sigma_{0}$ coordinates is very similar to the time-mean circulation in depth coordinates (not shown). Both exhibit an apparent deep upwelling across isopycnals, reaching $3000 \mathrm{~m}$ 


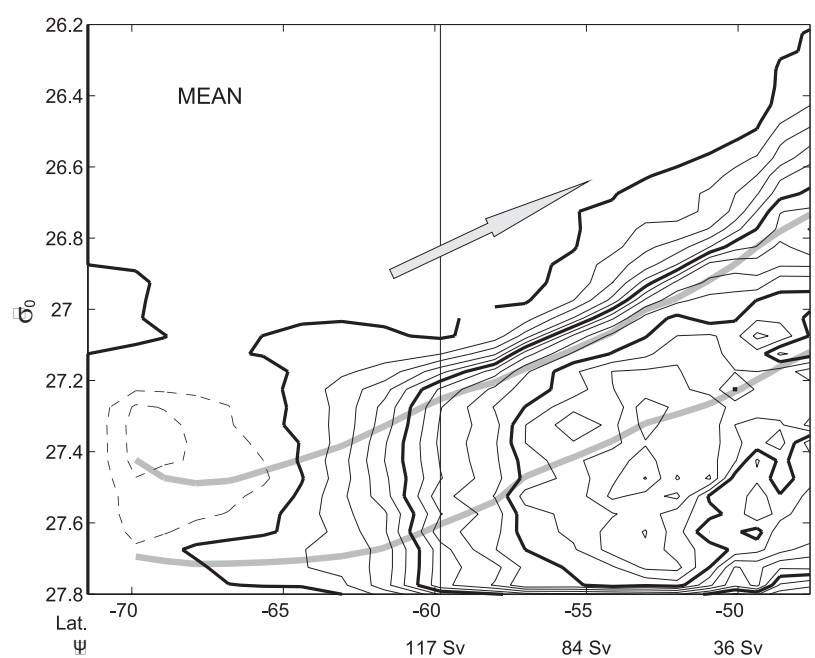

Fig. 9. Meridional transport streamfunction (time-mean flow only) calculated in density space as a function of $\sigma_{0}$, integrated along streamlines and plotted as a function of the mean latitude of each streamline. Positive values indicate a clockwise circulation. Dashed contours indicate negative values. Contour interval is $2 \mathrm{~Sv}$ and the contours 0,10 and $20 \mathrm{~Sv}$ are indicated by thick black lines. The thick grey lines indicate the $100 \mathrm{~m}$ and $500 \mathrm{~m}$ depth. The vertical line corresponds to the limit of the ACC belt.

(consider the vertical contours in Fig. 9 between $\sigma_{0}=27.6$ and 27.8). As expected, integrating along streamlines reduces the amplitude of the time-mean velocity-density correlations. In the zonal mean view, one does not need to take eddies into account to eliminate the Deacon cell, it is enough to integrate the time-mean flow in density classes. In a streamline view, it is only when considering the total meridional circulation (mean + transient) that we can recover a consistent picture without spurious deep upwelling or downwelling across time-mean isopycnals. Averaging zonally obscures the role of the transient eddies, while averaging following streamlines more clearly reveals their influence.

The eddy-driven meridional circulation across streamlines is shown in Fig. 10. The eddy contribution is poleward as expected, in the opposite direction to the mean flow. In the resulting total streamfunction (Fig. 11) the spurious crossisopycnal flow disappears. The residual circulation is $12 \mathrm{~Sv}$ equatorward, supplied by an upwelling along the sloping isopycnals at intermediate depths, south of the ACC belt. Our streamline-integrated view contrasts with the estimates of Lee et al. (2003) from the OCCAM $1 / 4^{\circ}$ model. Their Fig. 5 shows a very small contribution of eddies in the upper $500 \mathrm{~m}$. This difference may be due to a lower resolution of their model, or a less accurate determination of their streamlines. Our reference experiment, when analyzed in a streamline framework, is in qualitative agreement with the "conventional" view of the meridional circulation across the

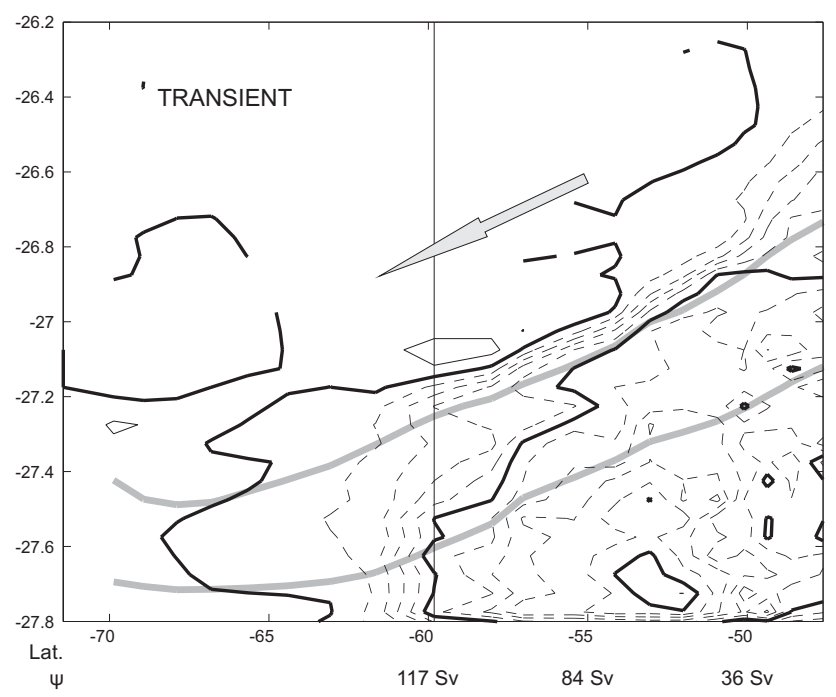

Fig. 10. Same as Fig. 9 for the transient meridional transport streamfunction calculated in density space as a function of $\sigma_{0}$, integrated along streamlines and plotted as a function of the mean latitude of each streamline.

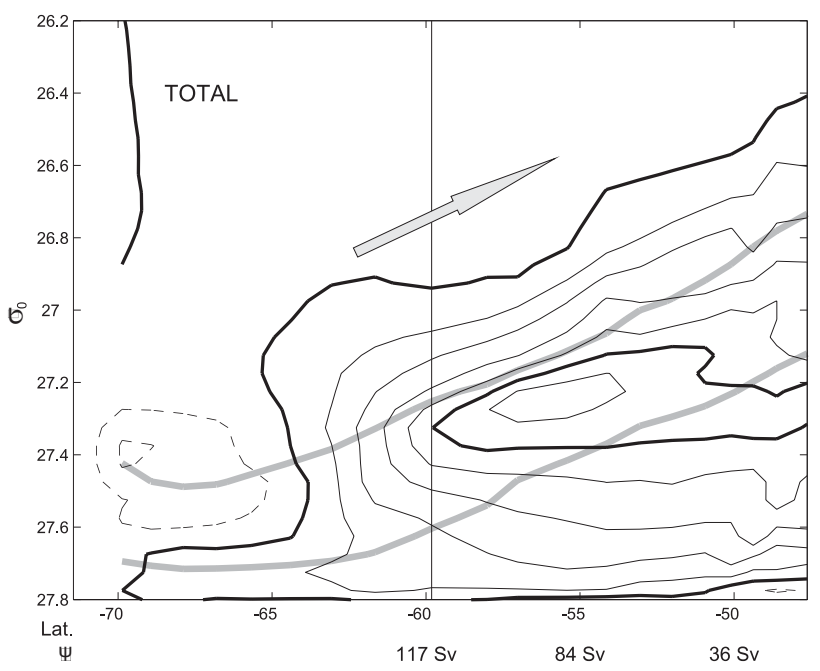

Fig. 11. Same as Fig. 9 for the total (residual) meridional transport streamfunction calculated in density space as a function of $\sigma_{0}$, integrated along streamlines and plotted as a function of the mean latitude of each streamline.

ACC: a time-mean equatorward flow near the surface, driven by Ekman drift, and partially cancelled by an eddy flux in the opposite direction. The cancellation is far from perfect in our solution: in the upper $500 \mathrm{~m}$ eddies cancel only $14 \mathrm{~Sv}$ out of the $26 \mathrm{~Sv}$ mean transport, leaving $12 \mathrm{~Sv}$ of residual equatorward circulation. 

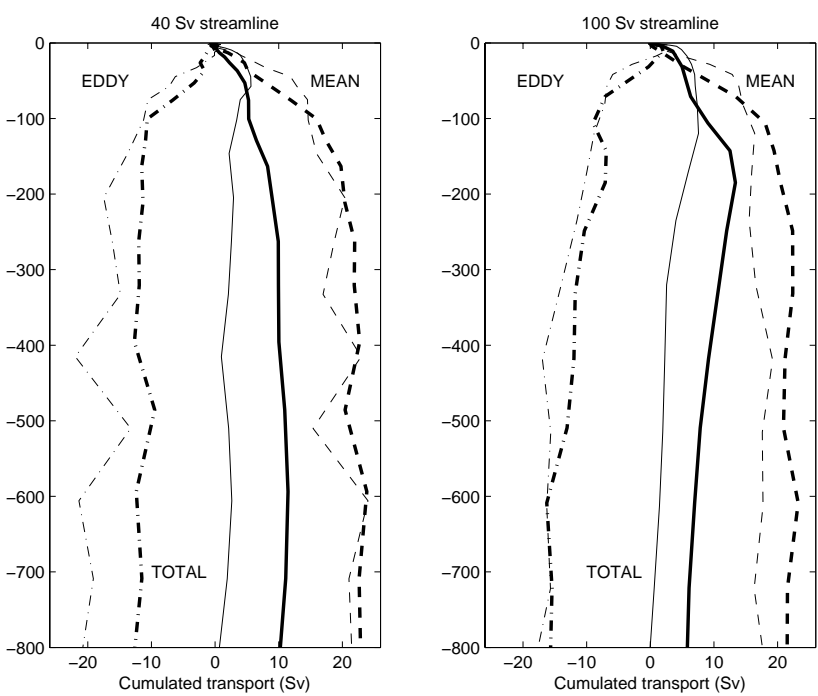

Fig. 12. Meridional transport streamfunction profiles, calculated in density space as in the previous figures, but replotted as a function of the isopycnal streamline-averaged depths. Two experiments are compared (the reference, bold lines; and the CORE experiment, thin lines). For both experiments the mean, eddy and total (residual) overturning are indicated by dashed, dashed-dotted, and continuous lines respectively. Left-hand panel: circulation across the $40 \mathrm{~Sv}$ ACC streamline, with average latitude $50.1^{\circ} \mathrm{S}$.; right-hand panel, circulation across the $100 \mathrm{~Sv}$ ACC streamline, with average latitude $57.2^{\circ} \mathrm{S}$.

Although the general picture fits with idealized models such as Marshall (1997) or Karsten and Marshall (2002), there is no quantitative agreement between our model solution and the simplified Eq. (3). In the equilibrium solution (3), the residual circulation changes sign when the buoyancy forcing changes sign. This is not the case when we compare our reference experiment with the CORE one. The residual circulation is weaker in the CORE run but still poleward, reaching $6.4 \mathrm{~Sv}$ on average in the core of the ACC. One question we want to point out about (3) is, at which depth should it be applied? It is apparent from Figs. 9-11 that both the mean and eddy overturnings have a complex vertical structure, so that the maximum residual circulation is set not only by the maximum mean and eddy component, but also by the way they compensate each other at different depths (or densities).

Figure 12 compares profiles of cumulative transport (integrated from the surface) across two ACC streamlines for the reference and CORE experiments. In both experiments the equatorward transport by the mean flow is partially compensated by poleward eddy transport. The mean equatorward transport is larger in the reference case, in accordance with the slightly larger Ekman transport (Fig. 5). Hallberg and Gnanadesikan (2006) find that an increase in the Ekman transport leads to an increase in the opposing eddy flux; this is not the case in our experiments. The most striking differ- ence between our two experiments is the vertical structure of the circulation. The residual transport increases much more rapidly from the surface in the CORE run, creating a maximum near $60 \mathrm{~m}$ as opposed to about $200 \mathrm{~m}$ in the reference run. The residual streamfunctions for the two experiments diverge most dramatically between 100 and $200 \mathrm{~m}$. In the reference case, the eddy transport is small in this depth range while the mean transport continues to increase with depth; as a result the residual circulation increases to a maximum near $200 \mathrm{~m}$. In the CORE experiment, the eddy transport increases with depth more rapidly than the mean transport below $100 \mathrm{~m}$, and the residual streamfunction is reduced to small positive values by $200 \mathrm{~m}$ depth. The larger eddy transport in the CORE case is consistent with the enhanced eddy energy in this run (Fig. 6).

The fact that the overturning streamfunctions differ most in the upper $200 \mathrm{~m}$ in the two experiments suggests the structure of the mixed layer may contribute to the different circulations. While the maximum mixed layer depths are similar in the reference and CORE cases, the annually averaged mixed layer depths are much shallower in CORE. This is likely due to the change in vertical mixing scheme (rather than the change in forcing), which was implemented with the specific objective of improving the summer mixed layer depths that were shallower than observed in the CORE run. Unfortunately, the ORCA025 model is too costly to perform multiple sensitivity experiments, changing one parameter at a time. In any case, the difference between the two runs illustrates that the relationship between the meridional circulation and buoyancy fluxes is not independent of the structure of the mixed layer and therefore vertical mixing, a fact illustrated by Olbers and Visbeck (2005). This dependency is hidden in equation by assuming that the relationship is valid at the base of the mixed layer. But in the real world, the mixed layer depth varies significantly with season and along streamlines (Fig. 7), so it is not possible to a priori decide at which depth the theory should be applied. In their analytical model, Olbers and Visbeck (2005) have tried to take into account mixing at the mixed layer base by considering a transition layer in which the isopycnal slopes change from infinity (in the mixed layer) to their interior values. They find that the simplified Eq. (3) does not hold in the presence of such a transition layer, even without breaking the zonal symmetry of the problem. Furthermore, we have used only the surface buoyancy forcing in (3) but Radko and Marshall (2003) estimate that diabatic eddy fluxes in the mixed layer are likely to represent a significant contribution.

\section{Depth-integrated balances}

In order to explore more deeply the relationship between buoyancy forcing and circulation, we would need to consider the complete temperature and salinity equations along streamlines in the mixed layer. In order to do this accurately 
in a numerical model it is necessary to store all the tendencies of the temperature and salinity equation terms at every grid point, which is not yet feasible in a global eddy-resolving model (such diagnostics are used by Iudicone et al., 2007 in a low resolution version of the same model). The largest difficulty comes from the vertical mixing terms, which are highly nonlinear due to the turbulent closure scheme and cannot be estimated from our archived 5-days output. It is still possible to consider depth integrated balances (in which case the vertical mixing term vanish identically). This is of interest for two reasons. First, heat and salt transports have only been published so far integrated in latitude bands, not following the ACC path. Second, the theoretical model expressed in Eqs. (4)-(5) relies on an equation for conservation of potential density written in flux form, which does not exist: integral conservation statements can be written for potential temperature and salt, but a similar equation for density contains additional source and sinks due to thermobaric and cabelling effects. In this section we try to evaluate the importance of the nonlinearity of the equation of state for the evolution of density in the whole ACC belt.

Table 2 shows various depth-integrated balances across the ACC belt for both the reference and the CORE experiment. Regarding the net water balance, the ACC belt gains water at a rate of $0.4 \mathrm{~Sv}$, which is compensated by an equivalent export northward. The small residual is the drift due to the rise of global sea surface height during that period. In the reference experiment the ACC belt loses heat through the surface flux at a rate of $0.11 \mathrm{PW}$. This is not compensated by the divergence of lateral heat transport $(0.01 \mathrm{PW})$, nor by the heat content drift $(0.01 \mathrm{PW})$. Rather, the surface cooling is compensated by the diffusive flux of heat along isopycnals. The model being eddy permitting, we have kept a Laplacian parameterization of isopycnal diffusion of potential temperature and salinity. This term being nonlinear, it is not possible to calculate it exactly from the 5-day average ouput of the model. The mixing coefficient at the northern latitude $\left(-47.6^{\circ} \mathrm{S}\right)$ is $200 \mathrm{~m}^{2} \mathrm{~s}^{-1}$. A rough calculation shows that with our Laplacian mixing coefficient a flux of $0.1 \mathrm{PW}$ is obtained with an isopycnal gradient of temperature of $1^{\circ} \mathrm{C}$ over a distance of $1000 \mathrm{~km}$, which is compatible with the strong gradients shown in Fig. 4 at the northern boundary of the ACC. This value is also compatible with the eddy diffusive heat transport calculated by Lee et al. (2007) from the OCCAM $1 / 12^{\circ}$ model. The importance of parameterized isopycnal diffusion is similar in the CORE case.

The eddy contribution to advective heat transport is also indicated in Table 2; it is the dominant contribution. At the northern boundary there is a large cancellation between the eddy flux (bringing heat southward) and the mean flux (bringing heat northward). This agrees with the conventional picture of the ACC, and with zonal mean curves of heat transport from various models that show a maximum eddy contribution just south of $40^{\circ} \mathrm{S}$ (Jayne and Marotzke, 2002; Lee et al, 2007). The poleward eddy heat transport $(0.73 \mathrm{Pw}$ north

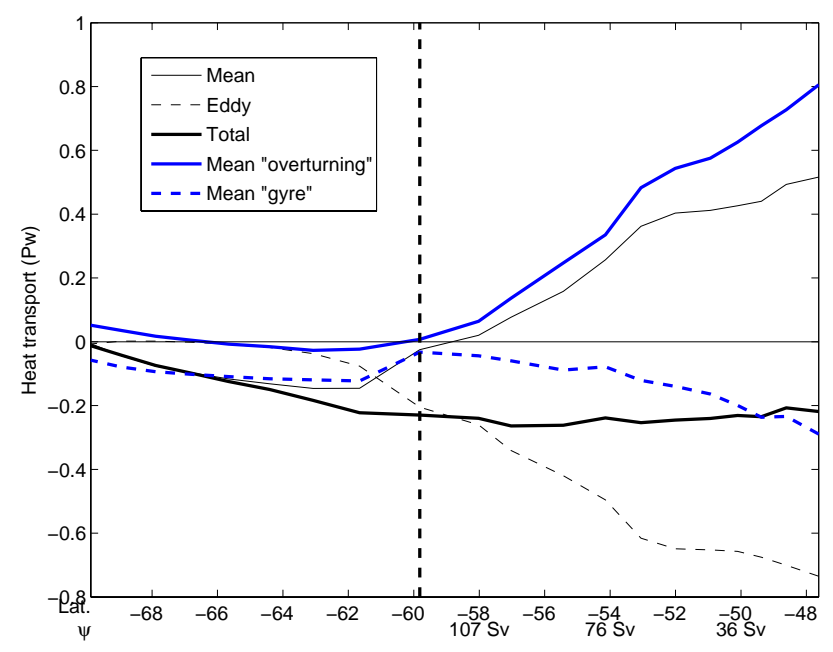

Fig. 13. Meridional depth-integrated heat transport across streamlines for the reference experiment. The total and eddy part correspond to the numbers in Table 2 for the north and south boundary of the ACC region (this south boundary is marked by a vertical black line). The time-mean heat transport (thin black line) is further decomposed into two terms, the "overturning" and "gyre" parts.

of the ACC and $0.21 \mathrm{Pw}$ to the south) compares well with the recent estimates of Gille (2003) based on ARGO data. It is interesting to compare the heat balance of the two model experiments with different forcings. The surface heat loss in the ACC is larger by a factor of three for the CORE experiment $(0.34 \mathrm{PW})$. This is due to a stronger heat loss in the south Pacific. The advective eddy heat flux is also larger in the CORE experiment (by 14\%) but the eddy flux divergence across the ACC belt is almost the same as in the reference experiment. The CORE experiment equilibrates by decreasing the northward advection of heat by the mean flow at the northern boundary (from $0.51 \mathrm{PW}$ to $0.30 \mathrm{PW}$ ). This importance of the heat transport by the mean flow across a mean streamline may seem surprising, so it is useful to consider the various components of heat transport in the streamline framework (Fig. 13). We decompose the time-mean heat transport into an "overturning" component, which is the transport of streamline-averaged temperature by the streamline-averaged velocity, and a "gyre" component which is due to the deviations from the streamline-average. The time-mean heat transport is mainly due to the "overturning" component, linked to the Ekman-driven surface transport compensated by a deep return flow. However, the "gyre" component is not negligeable. When we analyse the $0.21 \mathrm{PW}$ decrease in heat transport by the time-mean flow between the two experiments, we find that it is explained by a $0.15 \mathrm{PW}$ decrease of the overturning component (the Ekman transport being smaller in the CORE case) and a $0.06 \mathrm{PW}$ decrease in the "gyre" component. There is a sharp contrast in Fig. 13 between the ACC belt and the southern region, where eddies become less 
Table 2. Balances in the ACC belt for the reference and the CORE experiments. For advective fluxes, the first number is the total and the eddy contribution is indicated between braces. The flux convergence is the flux at the northern boundary minus the flux at the southern boundary; the sum of convergence and drift is expected to match the surface flux for the water, heat and density balance. For the salt balance the surface flux acts on local salinity but not on the integrated quantity of salt (it is indicated for completeness but marked with an asterisk). The residual of the heat and salt balances corresponds to the parameterized isopycnal diffusion of tracers in the model. To help the discussion, the balance is also indicated for a "pseudo density" which is a linear combination of potential temperature and salinity with constant coefficients $\hat{\alpha}$ and $\hat{\beta}$ chosen so as to match the haline and thermal components of the surface flux. For the reference experiment $\hat{\alpha}=1.05 \times 10^{-4}$ and $\hat{\beta}=7.54 \times 10^{-4}$; for the CORE experiment $\hat{\alpha}=-1.89 \times 10^{-4}$ and $\hat{\beta}=7.52 \times 10^{-4}$.

\begin{tabular}{|c|c|c|c|c|c|}
\hline \multicolumn{6}{|c|}{ Standard experiment } \\
\hline Term & $\begin{array}{l}\text { advective flux } \\
\text { south }\end{array}$ & $\begin{array}{l}\text { advective flux } \\
\text { north }\end{array}$ & $\begin{array}{l}\text { advective flux } \\
\text { convergence }\end{array}$ & $\begin{array}{l}\text { surface } \\
\text { flux }\end{array}$ & drift \\
\hline Water flux (Sv) & 0.32 & 0.72 & 0.4 & 0.41 & 0.01 \\
\hline Heat flux (PW) & $-0.23(-0.21)$ & $-0.22(-0.73)$ & $0.01(-0.53)$ & -0.11 & 0.01 \\
\hline Salt flux (Sv.PSU) & $1.3(2.3)$ & $5.7(-10.2)$ & $4.5(-12.5)$ & $-14.8^{*}$ & 0. \\
\hline$\hat{\sigma}_{0}$ flux $\left(10^{-6} \mathrm{Kg} \cdot \mathrm{s}^{-1}\right)$ & $7.0(7.1)$ & $10.1(11.4)$ & $3.1(4.2)$ & 3.1 & -0.3 \\
\hline Density flux $\left(10^{-6} \mathrm{Kg} \mathrm{s}^{-1}\right)$ & $4.3(4.8)$ & $11.7(14.3)$ & $7.4(9.5)$ & 3.1 & -0.9 \\
\hline \multicolumn{6}{|c|}{ CORE forcing experiment } \\
\hline Water flux (Sv) & 0.26 & 0.69 & 0.43 & 0.44 & 0.01 \\
\hline Heat flux (PW) & $-0.28(-0.30)$ & $-0.53(-0.83)$ & $0.25(-0.53)$ & -0.34 & 0.01 \\
\hline Salt flux (Sv.PSU) & $0.7(2.2)$ & $6.2(-11.3)$ & $5.5(-13.5)$ & $-15.5^{*}$ & 0. \\
\hline$\hat{\sigma}_{0}$ flux $\left(10^{-6} \mathrm{Kg} \cdot \mathrm{s}^{-1}\right)$ & $13.7(15.7)$ & $29.6(30.6)$ & $16.0(14.9)$ & 16.2 & -0.4 \\
\hline Density flux $\left(10^{-6} \mathrm{Kg} \mathrm{s}^{-1}\right)$ & $5.1(6.5)$ & $20.5(16.6$ & $15.4(10.1)$ & 16.2 & -0.8 \\
\hline
\end{tabular}

important and the "gyre" heat transport is dominant. This is because our calculation no longer follows streamlines there and becomes more similar to zonal averaging, cutting across the Ross and Weddell gyres.

Discussion of idealized solutions for the ACC (barotropic, or two layers quasigeostrophic models) often makes use of the fact that the heat or buoyancy transport across a mean streamline is almost entirely caused by the transient eddies. In the present case, due to the complex three-dimensional structure of the ACC and its compensated temperature and salinity variations, a streamline is very different from a contour of mean depth-averaged temperature (as used for example by Thompson et al., 1993, to highlight the contribution of eddies to heat transport in the FRAM model). In a realistic primitive equation model there is no way to define a line across which time-mean transports of buoyancy, heat and salt all vanish.

The balance of salt has also been calculated. The surface salinity flux is indicated for reference, but it is cancelled exactly by the concentration/dilution effect (Roullet and Madec, 2000), so that it does not enter the volume integrated balance of salt. The salt is well conserved in both experiments: the drift is negligible. There is a large cancellation between the eddy and mean fluxes of salt, but as in the case of the heat balance the residual flux convergence is non negligible (4.5 Sv PSU in the reference case and 5.5 in the CORE case). This term is balanced by the parameterized isopycnal diffusion of salt, which is likely to be important at the northern boundary of the ACC belt (considering salinity gradients onto isopycnals in Fig. 4). A further remark can be made about the parameterized isopycnal diffusion of heat and salt: it is large in the balance calculated within the ACC belt, but it is much smaller when considering a balance over a region bounded by latitude lines. This is because the northern boundary of the ACC follows precisely the largest isopycnal gradients. Meridional heat transports are usually calculated across latitude lines, and in that case parameterized diffusive fluxes are generally found negligeable in eddy resolving models.

As mentioned earlier, potential density is not conserved in the integral sense, due to the nonlinearity of the equation of state. Moreover, to define potential density a reference depth must be chosen, and none is adequate in the whole Southern Ocean where isopycnals undergo large vertical excursions. It is better to use neutral density as Iudicone et al., 2007, but at the present time there is no algorithm efficient enough to "label" neutral density in a large model output dataset like ORCA025. In this paper, the emphasis being on the upper ocean circulation, we mainly consider the potential density referenced at the surface $\left(\sigma_{0}\right)$.

To evaluate the effect of the nonlinear equation of state, let us first write the various terms of the balance in Table 2 for a "pseudo" density $\hat{\sigma}_{0}=\hat{\alpha} \theta+\hat{\beta} S$. This variable is exactly conserved by the model equations, because potential temperature 
$\theta$ and salinity $S$ are conservative and $\hat{\alpha}$ and $\hat{\beta}$ are constants. We choose those coefficients so that the thermal and haline $\hat{\sigma}_{0}$ surface flux integrated over the ACC belt match those calculated from the nonlinear equation of state. For the reference experiment $\hat{\alpha}=-1.0510^{-4}$ and $\hat{\beta}=7.5410^{-4}$. The balance for $\hat{\sigma}_{0}$ is written in flux form and depth-integrated so that only the surface cooling is relevant (the surface flux is positive, leading to a densification). Usually, water mass formation balances are not written in flux form (e.g. Speer et al., 2000). With our model (Boussinesq approximation and linearized free surface) the velocity divergence is exactly zero at all grid points except in the top layer. As a result, considering the equation in non-flux form would simply require adding two terms at the surface that balance each other (the terms of the volume equation, first line of Table 2). Here we prefer the flux form because it is the one usually considered for heat and salt balances.

Regarding the lateral fluxes for our "pseudo" density $\hat{\sigma}_{0}$ there is a northward flux south of the ACC belt (mainly due to the poleward eddy heat flux, the haline flux being smaller). There is a larger positive $\hat{\sigma}_{0}$ flux at the northern end of the ACC belt. This flux results from the fact that the eddy heat contribution dominates over the eddy haline contributions, while the time-mean haline and thermal contributions almost cancel each other. We find for $\hat{\sigma}_{0}$ a good balance between the sum of the advective flux convergence and the drift on one hand, and the surface flux on the other (the imbalance equals at most $8 \%$ of the surface flux). Such was not the case for heat and salt because the isopycnal diffusive flux was important. We assume that the diffusive flux is small for $\hat{\sigma}_{0}$ because it is a reasonable approximation of the true potential density near the northern boundary of the ACC belt, where the diffusive flux is large; and of course, there are no gradients of potential density along isopycnals. The cancellation of the residuals in the heat and salt equation when they are combined to form an equation for pseudo-density is further proof of our correct interpretation of the heat and salt balances.

Comparison between the $\hat{\sigma}_{0}$ balance and the true potential density balance (Table 2) helps interpret the latter. Let us consider the reference experiment. The forcing term is the same (by definition of $\hat{\sigma}_{0}$ ), but the advective fluxes are quantitatively different, especially in the south where they are much smaller for the true density. This is due to the nonlinearity of the equation of state, and more specifically the heat expansion coefficient $\alpha$. Although $\beta$ varies by less than $3 \%$ across the ACC belt at the surface, $\alpha$ varies by almost a factor of three, from $0.57 \times 10^{-4}$ to the south to $1.58 \times 10^{-4}$ to the north. The divergence of the potential density flux over the ACC belt thus includes a term proportional to the gradient of $\alpha$ between the north and south; this cabelling effect acts as a positive convergence of density and in effect doubles the net convergence (compare the convergence of advective fluxes for $\hat{\sigma}_{0}$ and the true potential density in Table 2). The importance of cabelling is not so large in the CORE experiment, because the balance is dominated by the strong cool- ing, which occurs near the northern boundary of the ACC belt and is compensated by large fluxes across the northern boundary. As a result, the fluxes at the south and the northsouth gradient of $\alpha$ are less important in the balance. The strong cooling in the CORE experiment is probably overestimated, and the reference experiment is likely more realistic. It is thus very likely that cabelling needs to be taken into account in any attempt to quantify the relationship between advective fluxes and surface forcing in the ACC belt. This is not taken into account in simplified models such as Karsten and Marshall (2002) or Olbers and Visbeck (2005).

\section{Conclusions}

We have presented a view of the dynamics and meridional circulation of the Antarctic Circumpolar Current in a streamline framework, using an eddying global model. We have calculated transports in density classes, because this is the best way to estimate the residual circulation in the mixed layer where the quasi-geostrophic approximation fails. Across streamlines in the upper layers, there is an equatorward transport by the mean flow which tends to be compensated by the eddy transport, in agreement with theories. Because of the complex three-dimensional structure and non-zonality of the ACC, the zonal average does not provide such a clear view. In the zonal average, our model (like two recent eddyresolving models) shows a poleward total transport of the lightest waters (opposite to the Ekman transport), and a relatively small eddy contribution. It seems that the effect of velocity-density correlations increases with model resolution, because the meridional excursions of the fronts are better resolved, so that an analysis following streamlines becomes even more necessary to make sense of the meridional circulation.

One fundamental question is the degree of cancellation of the mean and eddy circulations in the ACC. Our model solutions do not provide a definitive answer, but they suggest that it does not depend simply on surface buoyancy forcing as implied by Karsten and Marshall (2002), among others. We document two model solutions with very different degrees of cancellation: in our reference experiment the eddy component is half the mean, leading to a residual circulation of more than $10 \mathrm{~Sv}$; in the CORE sensitivity experiment the eddy component is of the same order as the mean, with a residual circulation close to zero below $400 \mathrm{~m}$ (but still as strong as $6.5 \mathrm{~Sv}$ near the surface). The reduction of the residual circulation agrees qualitatively with the reduction of the buoyancy gain over the ACC between the two runs; however the residual circulation has a complex vertical structure and there is no way to find a depth at which it agrees quantitatively with the buoyancy forcing in the way suggested by the simple theory. This is not surprising, considering that that the simple relationship between the surface buoyancy forcing and the residual circulation breaks down as soon as one 
assumes a transition of finite thickness between the mixed layer and the interior, as demonstrated by Olbers and Visbeck (2005). We note further that the eddy fluxes are larger in the case with smaller Ekman transport (contrary to the experiments of Hallberg and Gnanadesikan, where the strategy of wind vs. buoyancy forcing was different, and the eddy fluxes where found to grow with increased Ekman transport). Contrary to the Karsten and Marshall (2002) estimate, in our model, the residual circulation does not change sign in the upper layers within the ACC; the eddy component does not become dominant over the mean north of the polar front. This is true for both of our experiments.

Another question is the nature of the transient fluxes. In the model streamline average, they are directed down the mean thickness gradients, so that mixing coefficients relevant to the Gent and McWilliams parameterization can be inferred. In our case, as in Lee et al. (2007), Hallberg and Gnanadesikan (2006), or Eden (2006), the mixing coefficients are spatially variable, and mostly in the range 500 to $800 \mathrm{~m}^{2} \mathrm{~s}^{-1}$. This is much smaller than the values assumed by Karsten and Marshall (2002) which were close to $2000 \mathrm{~m}^{2} \mathrm{~s}^{-1}$. It is even unclear that the Gent and McWilliams parameterization is relevant to the transient fluxes calculated in the model. Firstly, this parameterization is meant to account for baroclinic instability, and we know that instability mechanisms are complex in the ACC and subject to strong topographic influence, as shown by Fig. 6. Secondly, what we have loosely called "eddy fluxes" in this paper includes all the transient effects, even the high frequency and seasonal response of the mixed layer. Because the time scales of those processes are similar to those of baroclinic eddies it is difficult to separate their effects.

Consideration of volume, heat and salt balances in the ACC shows that the model drift is small. Our results confirm the importance of isopycnal diffusion of heat and salt at the northern boundary of the ACC, studied in another context by Lee et al. (2007). Lee et al. (2007) calculated the isopycnal diffusivity due to their resolved eddies, and found it to be important in the zonal mean. The same mechanism is certainly represented in our model, but we have not tried to separate the advective and diffusive contributions. In our case, besides the mixing by resolved transient eddies, we find an important contribution of the parameterized isopycnal mixing, which is larger in the streamline average than in the zonal mean view because the isopycnal gradients of temperature and salt are largest following streamlines. Our calculations point out the possible importance of the nonlinearities of the equation of state in the density balance of the ACC: in our reference experiment those effects account for half the total potential density convergence.

The picture that emerges from our analysis is not one of a simple and direct relationship between surface buoyancy forcing and residual circulation, but rather a complex interplay between atmospheric forcing, vertical and horizontal mixing in the mixed layer, and the three-dimensional struc- ture of the circulation. As pointed out by Hallberg and Gnanadesikan (2006), different dynamical regimes associated with both barotropic and baroclinic instability, different forcings and different water-mass properties are encountered in the ocean basins following a streamline of the ACC. These are not small perturbations to a streamline-averaged theory as considered by Radko and Marshall (2006); rather, this complex three-dimensional structure is a key characteristic of the ACC. This is why two-dimensional theories and simple eddy parameterizations do not enable a prediction of the strength or even the direction of the residual circulation, although they do provide a useful first order description of the dynamics in a statistically steady state. Given the large variations of temperature and salinity following the ACC, our results suggest that the region could very well adjust to changes in atmospheric forcing without any change in the transient fluxes, by modifications of the time-mean heat and salt fluxes across streamlines as well as the amplitude of the cabbelling effect.

Acknowledgements. This work has been initiated during the visit of A. M. Treguier to CSIRO and the University of New South Wales, funded by the French CNRS, the Australian Research Council (ARC), and the French-Australian exchange program FAST-DEST. A. M. Treguier, G. Madec, J. le Sommer and J. M. Molines are supported by CNRS. M. England is supported by ARC. This study is supported in part by the Australian government's Cooperative Research Centre (CRC) program through the Antarctic Climate and Ecosystems CRC, by the Australian Greenhouse Office of the Department of Environment and Water Resources, and by CSIROs Wealth from Oceans National Research Flagship. Simulations with the ORCA025 model were carried out at the CNRS IDRIS computer centre in Orsay.

Edited by: A. J. G. Nurser

\section{References}

Andrews, D. G. and McIntyre, M. E.: Planetary waves in horizontal and vertical shear: the generalized eliassen-Palm relations and the mean zonal acceleration, J. Atmos. Sci., 33, 2031-2048, 1976.

Barnier, B., Madec, G., Penduff, T., Molines, J.M., Treguier, A.M., Le Sommer, J., Beckmann, A., Biastoch, A., Böning, C., Dengg, J., Derval, C., Durand, E., Gulev, S., Remy, E., Talandier, C., Theetten, S., Maltrud, M., McClean, J., and De Cuevas, B.: Impact of partial steps and momentum advection schemes in a global ocean circulation model at eddy permitting resolution, Ocean Dynam., doi:10.1007/s10236-006-0082-1, 2006.

Brodeau L.: Contribution à l'amélioration de la fonction de forcage des mod'eles de circulation générale océanique, $\mathrm{PhD}$ thesis, université Joseph Fourier Grenoble 1, 2007.

Danabasoglu, G., McWilliams, J. C., and Gent, P. R.: The role of mesoscale tracer transports in the global ocean circulation, Science, 264, 1123-1126, 1994.

de Boyer Montégut, C., Mignot, J., Lazar, A., and Cravatte, S.: Control of salinity on the mixed layer depth in the world ocean. Part I: General description, J. Geophys. Res., 112, C06011, doi:10.1029/2006JC003953, 2007 
Döös, K. and Webb, D.: The Deacon cell and other meridional cells of the Southern Ocean, J. Phys. Oceanogr., 24, 429-442, 1994.

Ducet, N., Le Traon, P. Y., and Reverdin, G.: Global high resolution mapping of ocean circulation form Topex/Poseidon and ERS-1 and 2, J. Geophys. Res., 105(C8), 19477-19498, 2000.

Eden, C.: Thickness diffusivity in the Southern Ocean, Geophys. Res. lets., L11606, doi:10.1029/2006/GL026157, 2006.

Gallego, B., Cessi, P., and McWilliams, J. C.: The Antarctic Circumpolar Current in equilibrium, J. Phys. Oceanogr., 34, 15711587, 2004.

Gent, P.R., Willebrand, J., McDougall, T. J., and McWilliams, J. C.: Parameterizing eddy-induced tracer transports in ocean circulation models, J. Phys. Oceanogr., 25, 463-474, 1995.

Gille, S.: Float observations of the Southern Ocean. Part II: Eddy fluxes, J. Phys. Oceanogr., 33, 1182-1196, 2003.

Held, I. and Schneider, T.: The surface branch of the zonally averaged mass transport circulation of the troposphere, J. Atmos. Sci., 56, 1688-1697, 1999.

Hallberg, R. and Gnanadesikan, A.: The Role of Eddies in Determining the Structure and Response of the Wind-Driven Southern Hemisphere Overturning: Results from the Modeling Eddies in the Southern Ocean (MESO) Project, J. Phys. Oceanogr., 36, 2232-2252, 2006.

Iudicone, D., Madec, G., and McDougall, T. J.: Water mass transformations in a neutral density framework and the key role of light penetration, J. Phys. Oceanogr., in press, 2007.

Ivchenko, V. O., Richards, K. J., and Stevens, D. P.: The dynamics of the Antarctic Circumpolar Current, J. Phys. Oceanogr., 26, 753-774, 1996.

Jayne, S. R. and Marotzke, J.: The oceanic eddy heat transport, J. Phys. Oceanogr. 32, 3328-3345, 2002.

Karsten, R. H. and Marshall, J.: Inferring the residual circulation of the Antarctic Circumpolar Current from observations using dynamical theory, J. Phys. oceanogr., 32, 3315-3327, 2002.

Large, W. and Yeager, S.: Diurnal to decadal global forcing for ocean and sea-ice models: the datasets and flux climatologies. NCAR technical note: NCAR/TN-460+STR, CGD division of the National Center for Atmospheric Research, Available on the GFDL CORE web site, 2004.

Lee, M. M. and Coward, A. C.: Eddy mass transport for the Southern Ocean in an eddy-permitting global ocean model, Ocean Modelling, 5, 249-266, 2003.

Lee, M. M., Coward, A. C., and Nurser, A. J.: Spurious diapycnal mixing of the deep waters in an eddy-permitting global ocean model, J. Phys. Oceanogr., 32, 1522-1535, 2002.

Lee, M. M., Nurser, A. J., Coward, A. C., and de Cuevas, B. A.: Eddy advective and diffusive transports of heat and salt in the Southern Ocean, J. Phys. Oceanogr., 37, 1376-1393, 2007.

Levitus, S., Boyer, T. P., Conkright, M. E., O’Brian, T., Antonov, J., Stephens, C., Stathopolos, L., Johnson, D., and Gelfeld, R.: World Ocean Database 1998, NOAA Atlas NESDID18, 1998.

Lythe, M. B. and Vaughan, D. G.: BEDMAP: a new ice thickness and subglacial topographic model of Antarctica. J. Geophys. Res., Solid Earth, 106, 11 335-11 351, 2001.
Mc Intosh, P. C. and Mc Dougall, T. J.: Isopycnal averaging and the residual mean circulation, J. Phys. Oceanogr., 26, 1655-1660, 1996.

Maltrud, M. E. and McClean, J. L.: An eddy resolving global $1 / 10^{\circ}$ ocean simulation, Ocean Modelling, 8, 31-54, 2005.

Marsh, R., Nurser, A. J., Megann, A. P., and New, A. L.: Water mass transformation in the Southern Ocean in a global isopycnal coordinate GCM, J. Phys. Oceanogr., 30, 1013-1045, 2000.

Marshall, D.: Subduction of water masses in an eddying ocean, J. Mar. Res., 55, 201-222, 1997.

Marshall, J. and Radko, T.: Residual-mean solutions for the Antarctic circumpolar current and its associated overturning circulation, J. Phys. Oceanogr., 33, 2341-2354, 2003.

Meijers, A. J., Bindoff, N. L., and Roberts, J. L.: On the total, mean and eddy heat and freshwater transports in the Southern hemisphere of a $1 / 8^{\circ}$ x $1 / 8^{\circ}$ global ocean model, J. Phys. Oceanogr., 37, 277-295, 2007.

Molines, J. M., Barnier, B., Penduff, T., Brodeau, L., Treguier, A. M., Theetten, S., and Madec, G.: Definition of the interannual experiment ORCA025-G70, 1958-2004. LEGI report, LEGIDRA-2-11-2006, available at http://www.ifremer.fr/lpo/drakkar, 2006

Olbers, D. and Ivchenko, V. O.: On the meridional circulation and balance of momentum in the southern ocean of POP, Ocean Dynam., 52, 79-93, 2001.

Olbers, D. and Visbeck, M.: A model of the zonally averaged stratification and overturning in the southern ocean, J. Phys. Oceanogr., 35, 1190-1205, 2005.

Polton, J. A. and Marshall, D. P.: Overturning cells in the Southern Ocean and subtropical gyres, Ocean Sci., 3, 17-30, 2007, http://www.ocean-sci.net/3/17/2007/.

Orsi, A. H., Withworth, T., and Nowlin, W. D.: on the meridional extent and fronts of the Antarctic Circumpolar current, Deep Sea Res., 42, 641-673, 1995.

Radko, T. and Marshall, J.: The Antarctic circumpolar current in three dimensions, J. Phys. Oceanogr., 36, 651-669, 2006.

Rintoul, S. R., Hughes, C. W., and Olbers, D.: The Antarctic circumpolar current system, Ocean circulation and climate, edited by: Siedler, G., Church, J., and Gould, J., international geophysics Series, vol 77, Academic Press, 271-302, 2001.

Roullet, G. and Madec, G.: Salt conservation, free surface and varying levels: a new formulation for an ocean GCM, J. Geophys. Res., 105, 23 927-23 942, 2000.

Sokolov, S. and Rintoul, S. R.: Structure of Southern Ocean fronts at $140^{\circ}$ E, J. Mar. Syst., 37, 151-184, 2002.

Sokolov, S. and Rintoul, S. R.: Multiple jets of the Antarctic Circumpolar current south of Australia, J. Phys. Oceanogr., 37, 1394-1412, 2007.

Speer, K., Rintoul, S., and Sloyan, B.: The diabatic Deacon cell, J. Phys. Oceanogr., 30, 3212-3222, 2000.

Thompson, S. R.: Estimation of the transport of heat in the Southern Ocean using a fine resolution Antarctic model, J. Phys. Oceanogr., 23, 2493-2497, 1993.

Trenberth, K. E., Caron, J. M., and Stepaniak, D. P.: The atmospheric energy budget and implications for surface fluxes and ocean heat transports, Clim. Dyn., 17, 259-276, 2001. 